This EarthArxiv.org preprint has been submitted for publication but has not yet undergone peer review, and is subject to change. Data used in this study are freely available at the NTU Data Repository (see DOI links at end of paper). We welcome comments and feedback. 


\title{
Wet rice cultivation was the primary cause of the earthquake-triggered Palu landslides
}

\author{
Authors: Kyle Bradley ${ }^{1,}{ }^{*}$, Rishav Mallick ${ }^{1}$, Dedy Alfian ${ }^{2}$, Harisma Andikagumi ${ }^{3}$, Benazir \\ Benazir $^{2}$, Gilles Brocard ${ }^{4}$, Guangcai Feng ${ }^{5}$, Emma M. Hill ${ }^{1,6}$, Judith Hubbard ${ }^{1,6}$, Jedrzej \\ Majewski $^{1}$, Ella Meilianda ${ }^{2}$, Adam Switzer ${ }^{1,6}$, Shengji Wei ${ }^{1,6}$, and Sang-Ho Yun ${ }^{7}$ \\ *Corresponding author Email: kbradley@ntu.edu.sg \\ ${ }^{1}$ Asian School of the Environment, Nanyang Technological University, Singapore \\ 2 Tsunami Disaster and Mitigation Research Center (TDMRC), Syiah Kuala University, \\ Banda Aceh, Indonesia \\ ${ }^{3}$ Department of Earth Sciences, Durham University, UK \\ ${ }^{4}$ School of Geosciences, University of Sydney, Australia \\ ${ }^{5}$ School of Geosciences and Info-Physics, Central South University, No.932 South Lushan \\ Road, Changsha, Hunan 410083 P.R. China \\ ${ }^{6}$ Earth Observatory of Singapore, Nanyang Technological University, Singapore \\ ${ }^{7}$ NASA Jet Propulsion Laboratory, Pasadena, California, USA
}

The death toll and economic impact of an earthquake are greatly exacerbated when landslides are triggered by strong ground motion ${ }^{1,2}$. These slides typically occur in two different contexts: localized failure of steep slopes that pose a major threat to life in areas below $^{3}$; and lateral spreading of nearly flat sediment plains due to shaking-induced liquefaction ${ }^{4}$, which can damage large areas of critical infrastructure ${ }^{5,6}$. Catastrophic landsliding triggered by the September 28, 2018 earthquake at Palu, Indonesia did not occur in either context, but produced both outcomes. Here, we show that major alluvial landsliding was a direct consequence of irrigation that activated a previously nonexistent liquefaction hazard. Aqueduct-fed wet rice cultivation raised the water table to near ground level, saturating sandy alluvial soils that liquefied in response to strong ground shaking and enabled extensive and large-displacement lateral spreads on slopes less than $1.5^{\circ}$. On slopes steeper than $1.5^{\circ}$, lateral spreads sourced long-runout landslides and debris flows that swept through villages below. This damage and loss of life would not have occurred in the absence of aqueduct-fed wet rice cultivation. Landsliding of gentle, irrigated alluvial slopes is an unrecognized anthropogenic hazard, particularly in seismically active, rice-growing areas of Asia.

On September 28, 2018, a $\mathrm{M}_{\mathrm{w}} 7.5$ earthquake was produced by rupture of the Palu-Koro Fault in central Sulawesi, Indonesia. This plate boundary strike-slip fault broadly defines the western edge of the Palu Valley ${ }^{7}$ (Figure 1A) and slips at a high rate of $\sim 42 \mathrm{~mm} / \mathrm{yr}^{8}$. Peak ground accelerations of $\sim 0.4-0.5 g$ were likely experienced within the valley during the earthquake ${ }^{9}$. Although initial damage reports focused on the dramatic effects of rapid tsunami inundation in Palu City, it soon became clear that land sliding within the alluvial valley to the south was also responsible for a large proportion of the more than 2000 estimated casualties ${ }^{10}$. The severity of this damage was surprising because the gently sloping, cultivated valley floor had not previously been identified as a site of major 
landslide potential.

Irrigated agriculture in the naturally dry Palu Valley is important to the regional economy. At the beginning of the $20^{\text {th }}$ century, the Dutch colonial government of the East Indies attempted to raise the standard of living of native populations and decrease the likelihood of famine through construction of modern tropical irrigation systems ${ }^{11}$. This effort centered on the construction of aqueducts that increased the reliability and productivity of wet rice cultivation and allowed double cropping ${ }^{12}$. The unlined Gumbasa Aqueduct was completed in $1913^{13}$ and carried diverted river water across the wide and gentle eastern slopes of the valley for over a century, until its partial destruction during the 28 September earthquake (Figure 1B).

The Gumbasa Aqueduct defines the upper elevation of earthquake-triggered landsliding in the eastern Palu Valley. Mapped surface fractures, sand blows, and pooled water indicating widespread liquefaction are associated with a broad zone of horizontal displacement below the aqueduct (Figure 1B). The dry land above the aqueduct shows little deformation and no evidence of liquefaction. Large areas of mostly intact land translated down surface slopes of approximately $1^{\circ}$. Within the area of Figure $1 \mathrm{~B}, 11.1 \mathrm{~km}^{2}$ of land moved more than 2 meters; $4.6 \mathrm{~km}^{2}$ moved more than 5 meters; and displacements locally exceeded 15 meters. This deformation is of a similar scale and magnitude as famous earthquake-triggered coastal lateral spreads ${ }^{5,6,14}$, but instead occurred in an alluvial fan setting.

The greatest loss of life due to landsliding at Palu can be attributed to four long-runout landslides, three of which originated as lateral spreads beneath the Gumbasa Aqueduct (Petobo, Sidera, and Sibulaya), and a fourth within west Palu City (Balaroa) where a smaller water channel divides dry land at higher elevation from lush city land that failed (Figure 1A,C-F). These slides occurred only where the surface slope exceeded $1.5^{\circ}$, and their breakaway zones all coincide with the main downslope transition from dry to irrigated land.

A shallow water table was the primary factor that activated lateral spreading and landsliding hazards, which were subsequently triggered by the earthquake. Quantitative mapping of deformation within the eastern Palu Valley slide area using sub-pixel correlation $^{15}$ of 3 meter resolution Planet satellite images ${ }^{16}$ (Figure $2 \mathrm{~A}$ ) and a new detailed classification of agricultural land use (Figure 2B) together show that flooded paddy cultivation is directly correlated with ground surface displacement and strain. Lateral spreading mainly occurred in areas of dense fields and paddies with little intervening forestland (Figure 2B). Irrigated fields and paddies below the aqueduct are zones of extensional strain (Figure 2C), while an area of mixed forest and paddies that transitions downslope into densely planted forest is contractional (Figure 2D). Swath profiles of surface displacement colored by classified land use show that the lateral spread is a composite slide, with areas of paddy cultivation forming local breakaways that integrate to produce higher displacements, and areas of forest land forming internal contractional toes even in areas that moved more than 5 meters (Figure 3).

The detailed distribution of sliding is explained by an irrigation system and cultivation scheme that generated different hydrological conditions in the shallow subsurface. While wet rice cultivation requires a near-surface water table and intense groundwater recharge by irrigation, coconut palm planted in well-drained sandy soil in the dry Palu Valley climate requires only moderate watering (Figure $4 \mathrm{~A}$ ). Because large slide displacements can only 
occur where a sufficiently thick liquefied layer exists, these spatial variations in ground water level exerted a fundamental control on the triggered landsliding at Palu. In particular, lateral spreading occurred only in areas that exceeded a critical density of floodirrigated land (Figure 2). Paddies located downslope of the toe of the slide likely also had a shallow water table, and do exhibit surface signs of liquefaction, but show no measurable horizontal displacement indicating lateral spreading (Figure 1B). This suggests that these paddy areas were stabilized by the surrounding less-irrigated land, or that finer-grained sediments in a more distal fan setting were less susceptible to widespread liquefaction.

The economy of Palu is highly dependent on continuous irrigation and is likely to remain so. Reconstruction in the aftermath of the 28 September earthquake must therefore recognize the ongoing hazard associated with irrigation. While the near-term probability of another large rupture of this segment of the Palu-Koro Fault has likely decreased in the wake of the recent earthquake, aftershocks and rupture of the main fault farther south are now more likely due to crustal static stress changes ${ }^{17}$. In addition, active faults may directly underlie the eastern Palu Valley ${ }^{18}$. The peak ground acceleration produced by the $\mathrm{M}_{\mathrm{W}} 7.5$ event on the Palu-Koro Fault could be matched by a smaller $\left(\mathrm{M}_{\mathrm{W}} 6.5\right)$ earthquake located underneath the irrigated area ${ }^{9}$. While the physical process of bulk volume reduction during ground shaking might seem to suggest that the hazard of liquefaction has been reduced in the slide area, re-liquefaction has been observed over multiple earthquake cycles elsewhere ${ }^{19}$ and cannot be ruled out at Palu.

Because lateral spreading typically affects lowland areas with a regional water table that can only locally be drawn down, engineering solutions to mitigate this hazard are expensive and invasive ${ }^{20}$. The naturally drained alluvial setting of the Palu Valley may offer more easily achievable solutions. Lateral spreads in alluvial fan settings are rare because the water table often lies well below the ground surface. Total displacements and areal extents of sliding described from other earthquake-triggered alluvial fan lateral spreads were small 21,22. Sufficiently lowering the water table beneath alluvial slopes of the Palu Valley could reduce the hazard of lateral spreading and landsliding (Figure 4B) by breaking the lateral connectivity of saturated liquefiable strata. A similar effect may have prevented alluvial lateral spreading despite extensive liquefaction during the 1999 Chi-chi earthquake, where groundwater pumping artificially lowered the water table ${ }^{23}$. An assessment of the role of groundwater recharge from leaking of the aqueduct is also necessary ${ }^{24}$, especially in areas where the aqueduct traverses slopes greater than $1.5^{\circ}$.

Rice agriculture has been a major driver of new irrigation projects in Asia and demand for rice is expected to continue to rise ${ }^{25}$. This infrastructural development has activated new and unappreciated landslide hazards in seismically active areas. While lateral spreading within the Aso Caldera during the 2016 Kumamoto earthquake sequence in Kyushu, Japan $^{26}$ has been attributed to amplification of ground shaking in the sedimentary basin, the affected area was planted in irrigated rice and an artificially high water table may have played a role. Aqueducts constructed along the steep walls of fault-bounded pull-apart basins of the Sumatran Fault in Indonesia ${ }^{27}$ could source landslides similar to those at Palu. Irrigation development in Myanmar, including construction of large reservoirs and aqueducts along the Sagaing Fault, is intended to promote paddy cultivation during the dry season ${ }^{28}$ but is also likely to locally increase liquefaction hazards. The Palu landslides highlight the dual hazard of earthquake-triggered lateral spreading and related landsliding in areas of wet rice cultivation on gentle alluvial slopes, which must be taken into account 
for both existing and new irrigation projects.

Author contributions: $\mathrm{KB}, \mathrm{RM}$, and $\mathrm{JH}$ led the analysis and produced the primary results and figures. KB led the writing and all authors contributed to writing and editing the manuscript. DA, EM, JM, AS, BB, and GB provided field observations and critical insights into liquefaction, landsliding, and irrigation methods at Palu. KB, GF, and SW produced the displacement maps. HA mapped liquefaction features and produced the land use classification. EH and SY provided insight into damage mapping, recovery, and ground surface deformation at Palu.

Acknowledgements: This research was supported by the Asian School of the Environment of Nanyang Technological University, Singapore; the Earth Observatory of Singapore; the National Research Foundation Singapore; and the Singapore Ministry of Education. JH is supported by a Singapore National Research Foundation Fellowship (Award No. NRFNRFF2013-06). The authors declare no competing interests. 

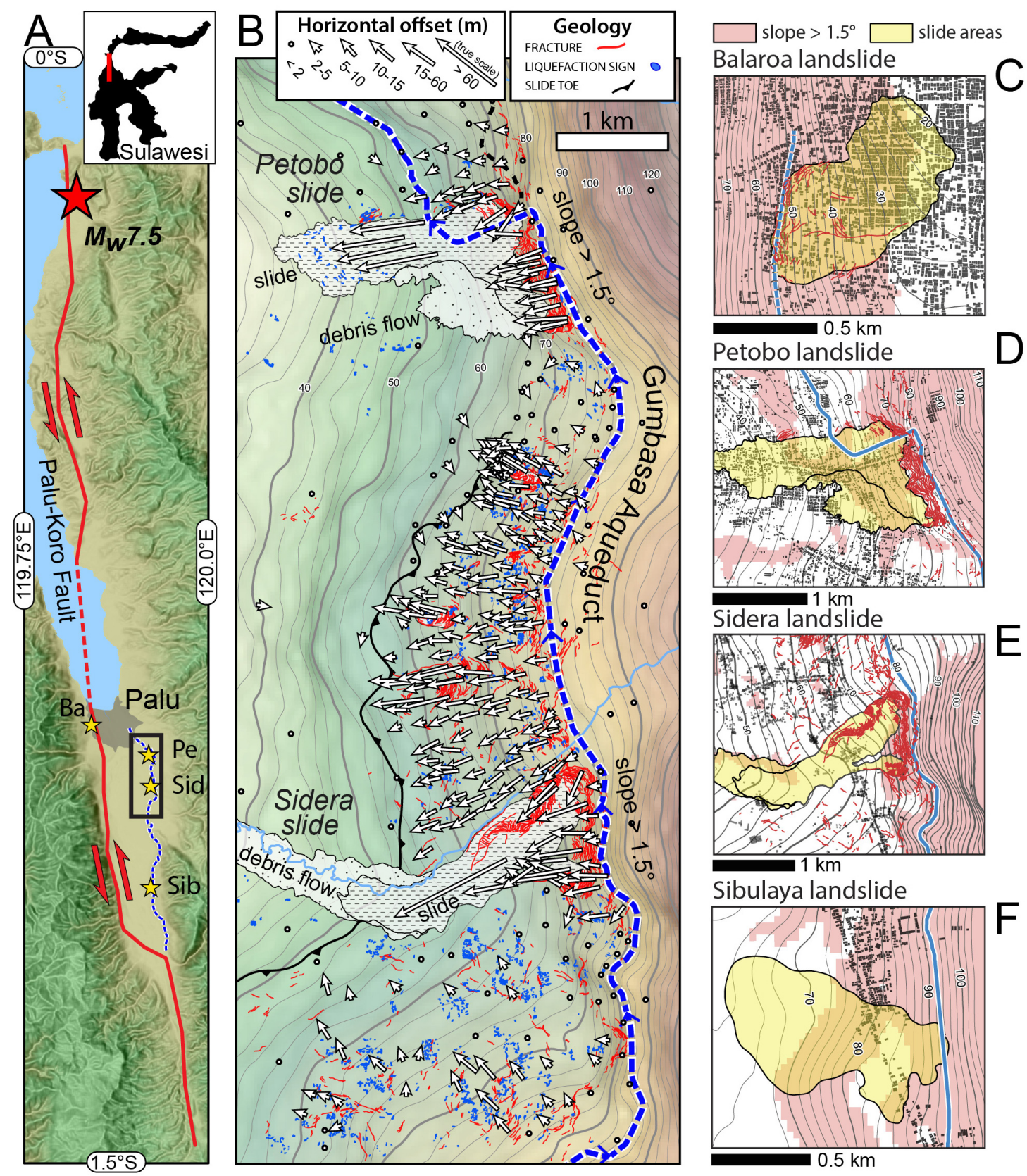

Figure 1. Earthquake-triggered landsliding in the Palu Valley, Sulawesi, Indonesia. A) Surface rupture of the September 28, $2018 \mathrm{Mw}$ 7.5 Palu earthquake. Box shows the area of panel 1B. Stars show locations of four long-runout landslides (Ba: Balaroa; Pe: Petobo; Sid: Sidera; Sib: Sibulaya) B) Area of lateral spreading and landsliding beneath the Gumbasa Aqueduct, showing surface fractures, liquefaction features including pooled water and sand blows, and observed surface displacements. C-F) Site maps of long-runout landslides sourced from lateral spreads in irrigated areas with surface slope steeper than $1.5^{\circ}$. Locations are given in panel 1A. Building footprints are from OpenStreetMap. 

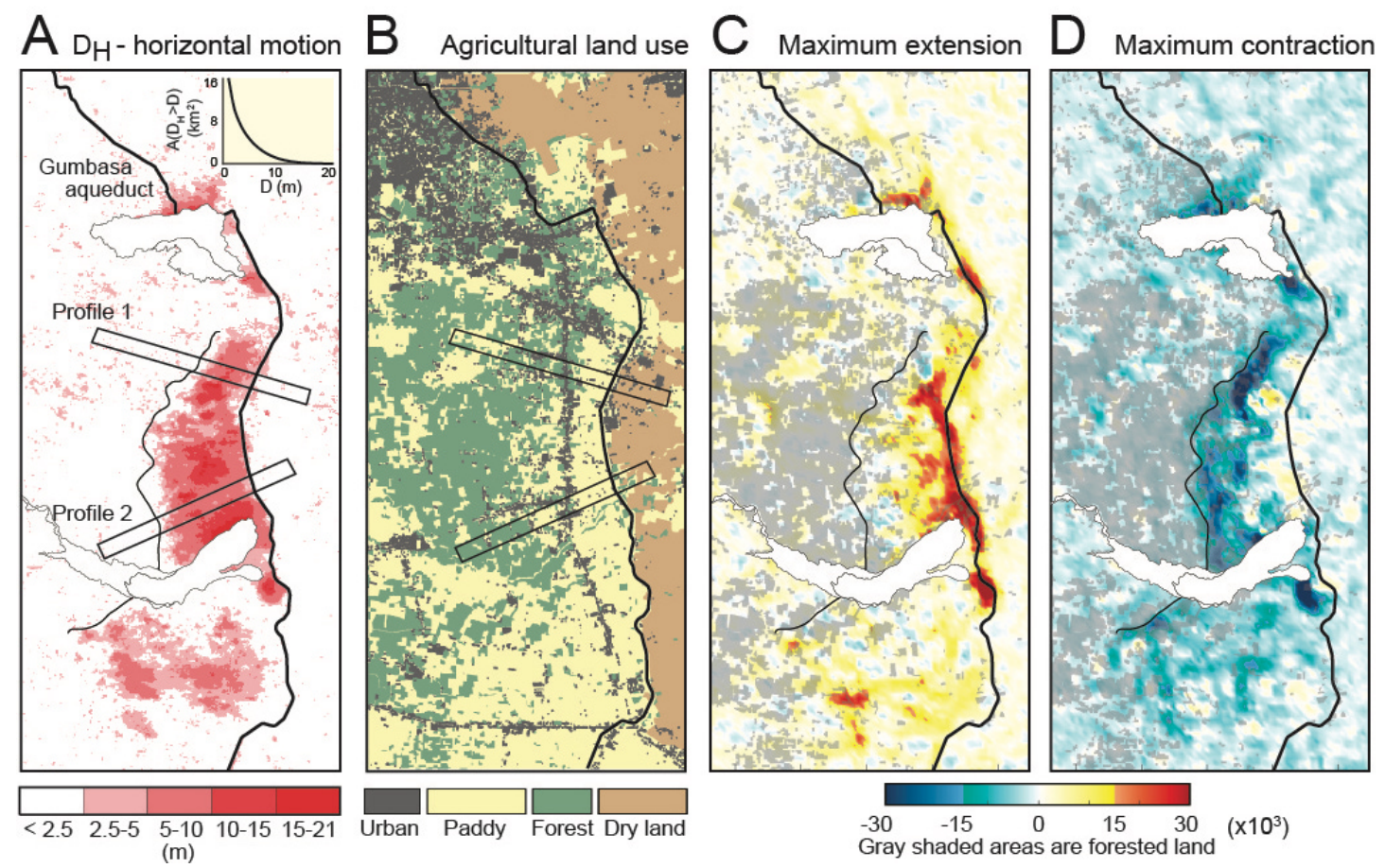

Figure 2. Landsliding in the eastern Palu Valley was intimately related to agricultural land use and irrigation. A) Horizontal displacements $\left(\mathrm{D}_{\mathrm{H}}\right)$ measured using sub-pixel correlation of pre- and post-event Planet satellite imagery. Inset shows the area of sliding exceeding a given displacement magnitude. Long-runout landslides and debris flows are masked. B) Classified land showing high density of flood irrigated paddies below the Gumbasa Aqueduct, dry land above, and forested land intermixed with paddies farther downslope. C) Extensional strain occurs along and beneath the aqueduct. D) Contractional strain occurs within mixed forest and irrigated areas located above a downslope transition to dense trees. 

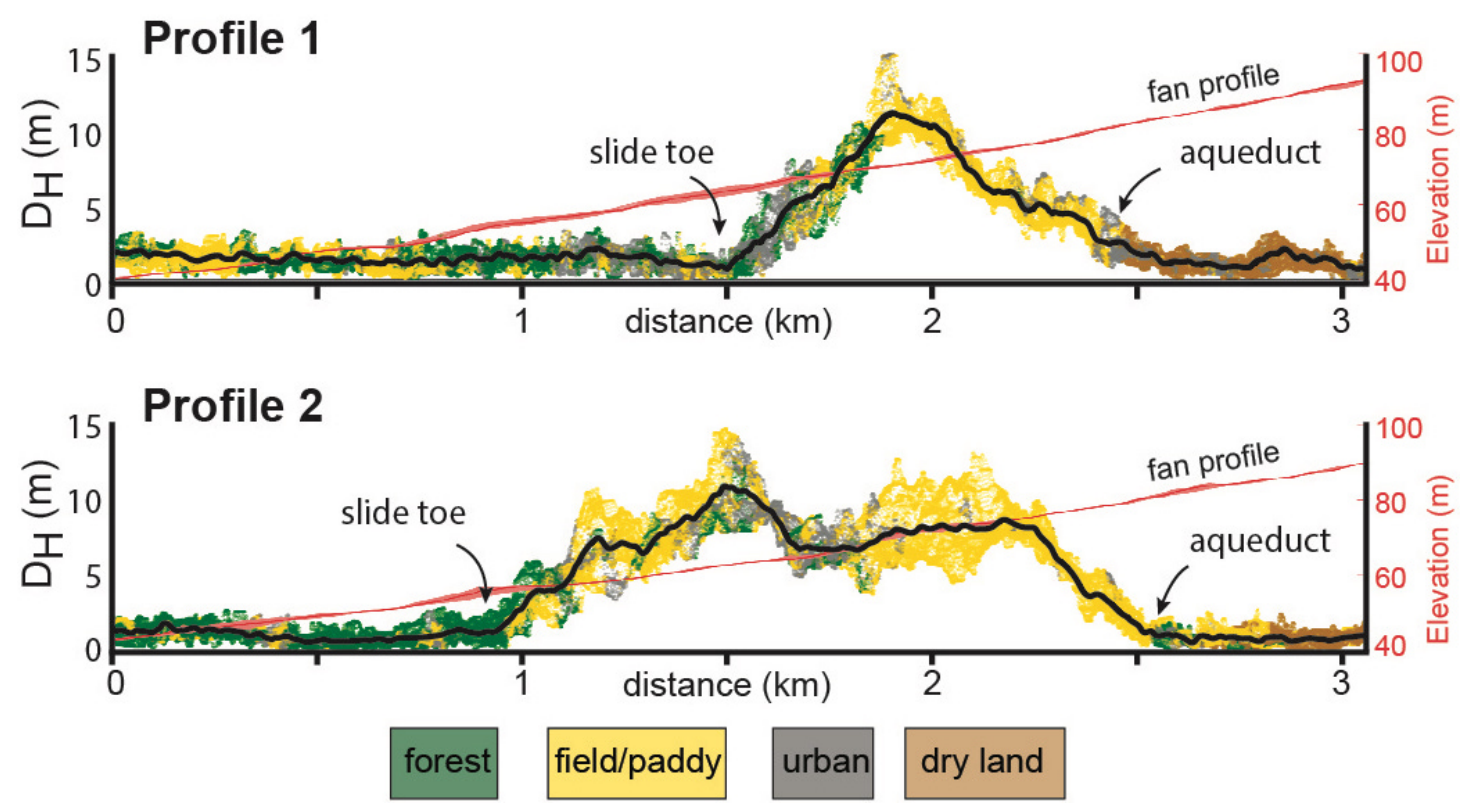

Figure 3. Swath profiles of horizontal displacement $\left(\mathrm{D}_{\mathrm{H}}\right)$ colored by classified land use. Profile locations are given in Figure 2A-B. Slide kinematics are correlated with land use type, with paddy areas forming breakaway zones and forest areas forming compressive toes. Profile 1 crosses a single slide with a breakaway zone at the Gumbasa aqueduct, while Profile 2 shows a composite slide with multiple breakaways and internal toe zones. 

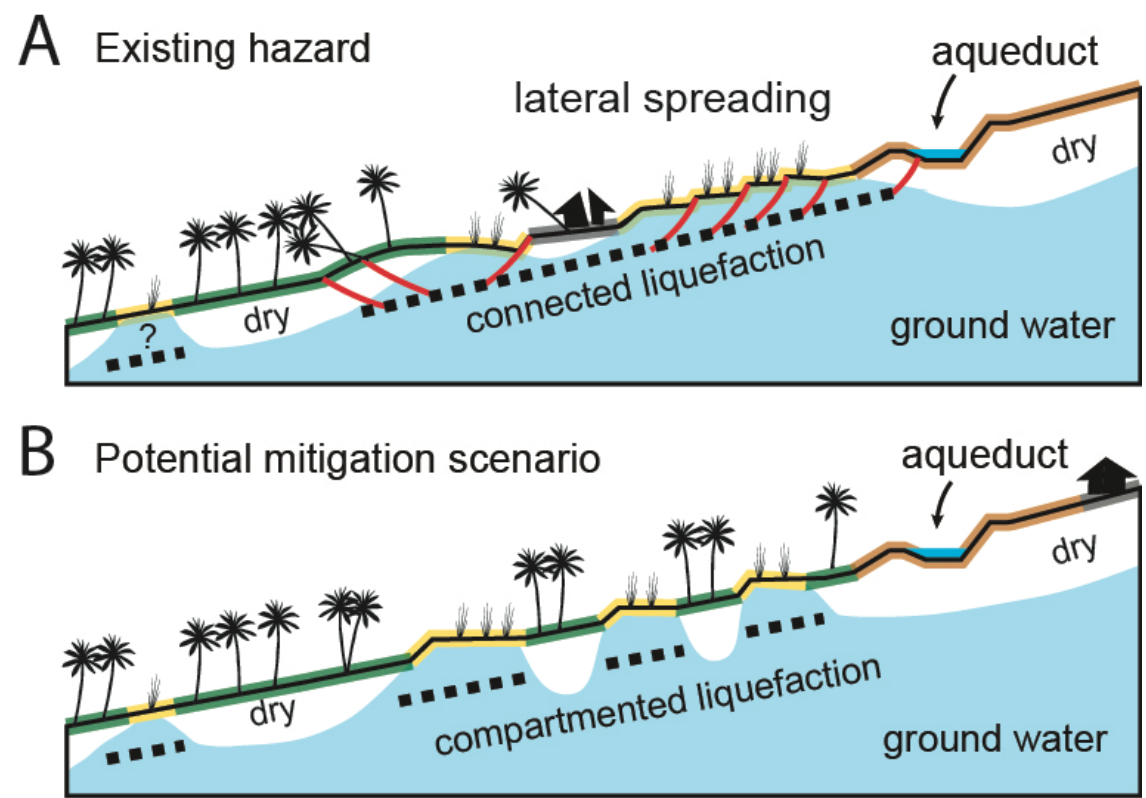

Figure 4. Anthropogenic liquefaction and landslide hazard at Palu, and one potential mitigation scenario. A) Schematic representation of irrigation-activated liquefaction and earthquake-triggered lateral spreading in the eastern Palu Valley. B) Liquefaction hazard can be at least partially mitigated, while maintaining the economic benefit of aqueduct irrigation, by reducing the lateral connectivity of saturation of liquefiable sediments in areas below the aqueduct.

\section{Methods}

\section{Geological mapping}

Ground surface ruptures and liquefaction features were identified using post-event high resolution Digital Globe satellite imagery in Google Earth Pro. In areas of very high rupture density, fault traces were mapped schematically in order to capture the geometry and extent of fracturing. Many surface traces are likely to have been missed due to vegetative or urban cover, mis-orientation to the preferable lighting direction, or subtlety of the trace. The fault map is therefore intended to be a visual representation of the location and surface geometry of faults and is not presented as a complete assessment of the complex surface fracturing. Standing water, light colored sand blows, and dark colored saturated surface soil were also manually mapped by the same method.

\section{Land Use}

We classified land use in the study area using four general categories: 1) urban land consisting mainly of buildings, 2) irrigated fields dominated by rice paddies, 3) forested 
land, and 4) non-irrigated dry land, both cultivated and uncultivated. Classification of category 1) was done using the hyperspectral band of the pre-event Planet imagery and building footprints from OpenStreetMap surrounded by a 10 meter buffer. Categories 2) and 3) were mapped by manual inspection of pre- and post-event Digital Globe imagery in Google Earth Pro, supplemented by canopy mapping from DEMNAS (see following section), and validated using post-event DigitalGlobe imagery to update areas of recent land use change. Category 4) was classified manually using DigitalGlobe imagery in Google Earth Pro.

\section{Topography}

In the study area and particularly along lower alluvial slopes, remotely-sensed topographic datasets are contaminated by a dense canopy of agricultural trees, primarily coconut palm. These tall ( $>20$ meter) trees are planted densely enough that DEMs derived from radar and optical datasets exhibit a patchwork of excessively high areas interspersed with true ground level covered by fields and paddies. This gives the false impression of a lower fan surface that is disrupted by erosional or tectonic effects, when in reality the fan surface is smooth. We sampled the Indonesian national 8.5-meter resolution Indonesian national DEM (DEMNAS) at 4,132 low areas corresponding with fields and paddies, and calculated an Inverse-Distance-Weighted height field from those points. We subtracted this from the original DEM to obtain a ground surface model and a vegetation height map. The height map was used to further refine our visual land classification to include areas where woody vegetation exists but is difficult to visually assess in satellite imagery.

\section{Displacement mapping}

North-south and east-west displacements were created using sub-pixel correlation using the freely available and open source software MicMac (v1.0.beta13). We used 3 meter resolution Planet satellite imagery captured on September 27 and October 1, projected into a WGS1984 UTM50S (EPSG:32750) grid. We used a 9x9 pixel correlation window and a preferred search azimuth of $270^{\circ}$. Larger correlation windows were tested but did not significantly improve the result. The resulting NS and EW displacement fields were detrended to minimize the average displacement value on the east side of the aqueduct and to remove artifacts resulting from imperfect original referencing of pre- and post-event satellite images. The magnitude of this correction was between of 1.1 pixels along the 
western edge of the study area and 0.3 pixels along the eastern edge.

Total displacements of identifiable ground-level features (arrows in Figure 1B) were mapped using high-resolution Digital Globe imagery in Google Earth Pro. A uniform shift correction was applied to account for systematic mismatch of pre-and post-event images, by minimizing the displacement of points located in undisturbed areas above the aqueduct.

\section{Strain calculation}

We calculate strain using the n-nearest neighbor method. We define a grid of $\left(\mathrm{x}_{\mathrm{g}}, \mathrm{y}_{\mathrm{g}}\right)$ $100 \times 200$ points, equally spaced over the region in which we have the MicMac displacement field $(\mathrm{u}, \mathrm{v})$ defined for every $(\mathrm{x}, \mathrm{y})$ location. We compute the horizontal displacement

gradient tensor $\frac{d u}{d x}, \frac{d v}{d x}, \frac{d u}{d y}, \frac{d v}{d y}$ from the displacement field $(\mathrm{u}, \mathrm{v})$ at each grid point $\left(\mathrm{x}_{\mathrm{g}}, \mathrm{yg}_{\mathrm{g}}\right)$ using least squares. We use $n=10$ nearest data points assuming that the strain field within the polygon created by the sorted stations is uniform. We extract the symmetric part of the displacement gradient tensor as the strain tensor $\epsilon_{x x}, \epsilon_{x y}, \epsilon_{y y}$, and we rotate the strain tensor to obtain the principal strains $\epsilon_{p}=\frac{\epsilon_{x x}+\epsilon_{y y}}{2} \pm \sqrt{\left(\frac{\epsilon_{x x}-\epsilon_{y y}}{2}\right)^{2}+\epsilon_{x y}^{2}}$.

\section{Data Availability}

The data required to reproduce our conclusions are available at the NTU Data Repository (https://researchdata.ntu.edu.sg/). The data included are: horizontal displacements, strain maps, land use classification, and mapped geological features. Prior to publication, reviewers and editors may use the following private links to access the data. Upon publication, this Dataverse will be made public.

MicMac displacement maps:

https://researchdata.ntu.edu.sg/privateurl.xhtml?token=cb21fea9-d338-441f-9d8cee8ed5820b9e

Strain rasters:

https://researchdata.ntu.edu.sg/privateurl.xhtml?token $=660915 \mathrm{cb}-6 \mathrm{c} 8 \mathrm{e}-40 \mathrm{~cd}-\mathrm{bfab}-$ e00a25b9213d

Measured displacements:

https://researchdata.ntu.edu.sg/privateurl.xhtml?token=1c185c24-9a2d-4701-95c7ae052b8cb74d

Geological feature KMZ files: 
https://researchdata.ntu.edu.sg/privateurl.xhtml?token=228295d0-6722-4bda-ab65$383 \mathrm{c} 5 \mathrm{fe} 0 \mathrm{~b} 57 \mathrm{~b}$

Land use classification:

https://researchdata.ntu.edu.sg/privateurl.xhtml?token=9ce23519-9dbd-46e9-ab35$10293 \mathrm{~d} 2819 \mathrm{e} 8$

\section{References}

1 Meunier, P., Hovius, N. \& Haines, A. J. Regional patterns of earthquake-triggered landslides and their relation to ground motion. Geophys Res Lett 34, doi:Artn L20408 10.1029/2007gl031337 (2007).

2 Keefer, D. K. Investigating landslides caused by earthquakes - A historical review. Surv Geophys 23, 473-510, doi:Doi 10.1023/A:1021274710840 (2002).

Dai, F. C. et al. Spatial distribution of landslides triggered by the 2008 Ms 8.0 Wenchuan earthquake, China. J Asian Earth Sci 40, 883-895, doi:10.1016/j.jseaes.2010.04.010 (2011). Wang, C. Y. Liquefaction beyond the Near Field. Seismol Res Lett 78, 512-517, doi:DOI 10.1785/gssrl.78.5.512 (2007).

5 Seed, H. B. Landslides during earthquakes due to liquefaction. Journal of Soil Mechanics \& Foundations Div (1968).

6 Seed, H. B. \& Idriss, I. M. Analysis of soil liquefaction: Niigata earthquake. Journal of the Soil Mechanics and Foundations Division 93, 83-108 (1967).

7 Bellier, O. et al. High slip rate for a low seismicity along the Palu - Koro active fault in central Sulawesi (Indonesia). Terra Nova 13, 463-470 (2001).

8 Socquet, A. et al. Microblock rotations and fault coupling in SE Asia triple junction (Sulawesi, Indonesia) from GPS and earthquake slip vector data. J Geophys Res-Sol Ea 111, doi:Artn B08409 10.1029/2005jb003963 (2006).

9 Ambraseys, N. N., Douglas, J., Sarma, S. K. \& Smit, P. M. Equations for the Estimation of Strong Ground Motions from Shallow Crustal Earthquakes Using Data from Europe and the Middle East: Horizontal Peak Ground Acceleration and Spectral Acceleration. Bulletin of Earthquake Engineering 3, 1-53, doi:10.1007/s10518-005-0183-0 (2005).

10 Centre, A. Situation update No. 15 - Final M 7.4 Earthquake \& Tsunami, Sulawesi, Indonesia. (2018).

11 Bertrand, R. La « politique éthique » des Pays-Bas à Java (1901-1926). Vingtième Siècle. Revue d'histoire 93, 115-138, doi:10.3917/ving.093.0115 (2007).

12 Kreisel, W., Weber, R. \& Faust, H. Colonial Interventions on the Cultural Landscape of Central Sulawesi by "Ethical Policy": The Impact of the Dutch Rule in Palu and Kulawi Valley, 1905-1942. 31, 398, doi:https://doi.org/10.1163/156853103322895324 (2003).

13 Metzner, J. Palu (Sulawesi): Problematik der Landnutzung in einem klimatischen Trockental am Äquator (Palu (Sulawesi): Problems of Land Utilization in a Climatic Dry Valley on the Equator). Erdkunde 35, 42-54 (1981).

14 Cubrinovski, M. et al. Soil Liquefaction Effects in the Central Business District during the February 2011 Christchurch Earthquake. Seismol Res Lett 82, 893-904, doi:10.1785/gssrl.82.6.893 (2011).

15 Rosu, A. M., Pierrot-Deseilligny, M., Delorme, A., Binet, R. \& Klinger, Y. Measurement of ground displacement from optical satellite image correlation using the free open-source software MicMac. Isprs J Photogramm 100, 48-59, doi:10.1016/j.isprsjprs.2014.03.002 (2015). 
Team, P. Planet Application Program Interface: In Space for Life on Earth. , $<$ https://api.planet.com.> (2017).

17 King, G. C. P., Stein, R. S. \& Lin, J. Static Stress Changes and the Triggering of Earthquakes. $B$ Seismol Soc Am 84, 935-953 (1994).

18 Watkinson, I. M. \& Hall, R. Fault systems of the eastern Indonesian triple junction: evaluation of Quaternary activity and implications for seismic hazards. Geological Society, London, Special Publications 441, SP441.448, doi:10.1144/sp441.8 (2016).

19 Yasuda, S. \& Tohno, I. Sites of reliquefaction caused by the 1983 Nihonkai-Chubu earthquake. Soils and Foundations 28, 61-72 (1988).

20 Yasuda, S. \& Harada, K. Measures developed in Japan after the 1964 Niigata Earthquake to counter the liquefaction of soil. (2014).

21 Holzer, T. L., Bennett, M. J., Ponti, D. J. \& Tinsley, J. C. Liquefaction and soil failure during 1994 Northridge earthquake. J Geotech Geoenviron 125, 438-452, doi:Doi 10.1061/(Asce)1090-0241(1999)125:6(438) (1999).

22 Youd, T., Harp, E., Keefer, D. \& Wilson, R. The Borah Peak, Idaho Earthquake of October 28, 1983-Liquefaction. Earthquake spectra 2, 71-89 (1985).

23 Wang, C. Y., Cheng, L. H., Chin, C. V. \& Yu, S. B. Coseismic hydrologic response of an alluvial fan to the 1999 Chi-Chi earthquake, Taiwan. Geology 29, 831-834, doi:Doi 10.1130/00917613(2001)029<0831:Chroaa>2.0.Co;2 (2001).

24 Harvey, F. E. \& Sibray, S. S. Delineating Ground Water Recharge from Leaking Irrigation Canals Using Water Chemistry and Isotopes. Groundwater 39, 408-421, doi:doi:10.1111/j.1745-6584.2001.tb02325.x (2001).

25 Neumann, K., Verburg, P. H., Stehfest, E. \& Muller, C. The yield gap of global grain production: A spatial analysis. Agr Syst 103, 316-326, doi:10.1016/j.agsy.2010.02.004 (2010).

26 Fujiwara, S., Morishita, Y., Nakano, T., Kobayashi, T. \& Yarai, H. Non-tectonic liquefactioninduced large surface displacements in the Aso Valley, Japan, caused by the 2016 Kumamoto earthquake, revealed by ALOS-2 SAR. Earth Planet Sc Lett 474, 457-465, doi:10.1016/j.epsl.2017.07.001 (2017).

27 Sieh, K. \& Natawidjaja, D. Neotectonics of the Sumatran fault, Indonesia. J Geophys Res-Sol Ea 105, 28295-28326, doi:Doi 10.1029/2000jb900120 (2000).

28 Naing, T. A. A., Kingsbury, A. J., Buerkert, A. \& Finckh, M. R. A Survey of Myanmar Rice Production and Constraints. J Agr Rural Dev Trop 109, 151-168 (2008). 